Journal of Applied Pharmaceutical Science Vol. 6 (02), pp. 115-118, February, 2016

Available online at http://www.japsonline.com

DOI: $10.7324 / J A P S .2016 .60217$

ISSN 2231-3354 (cc) EY-NC-SA

\title{
An evaluation of Metered-Dose Inhaler Administration Technique in Patients of Asthma and Chronic Obstructive Pulmonary Disease
}

\author{
Alpesh Chauhan ${ }^{1 *}$, Prakruti Patel ${ }^{2}$, Anuradha Gandhi ${ }^{2}$, Mira Desai ${ }^{2}$ \\ ${ }^{1}$ Department of Pharmacology, Smt Kashibai Navale Medical College, Pune, Maharashtra, India. \\ ${ }^{2}$ Department of Pharmacology, B.J. Medical College, Ahmedabad, Gujarat, India.
}

\begin{tabular}{l} 
ARTICLE INFO \\
\hline Article history: \\
Received on: 07/09/2015 \\
Revised on: $20 / 10 / 2015$ \\
Accepted on: 19/11/2015 \\
Available online: $27 / 02 / 2016$ \\
\hline Key words: \\
Asthma, Chronic Obstructive \\
Pulmonary Disease, Metered \\
Dose Inhaler.
\end{tabular}

\begin{abstract}
Objectives: To evaluate the technique of use of metered dose inhaler (MDI) in patients of asthma or chronic obstructive pulmonary disease (COPD) patients at a tertiary health care hospital.

Materials and methods: This was a cross-sectional observational study conducted in the patients of bronchial asthma and COPD who were prescribed MDI. The method to use MDI was assessed by using checklist made by WHO Guide to Good Prescribing.

Results: A total of 193 patients (128 COPD, 65 asthma) were included. Majority of patients (95\%) were educated by the treating physician for the use of inhalational technique of MDI. Majority of patients (98.4\%) followed the step to place the lips tightly around the mouthpiece. While the least followed steps were coughing up as much sputum as possible $(14.5 \%)$, breathing out through nose $(15 \%)$ and rinsing the mouth after use $(22.8 \%)$.

Conclusion: Few steps of MDI use were missed in majority of the patients. This can be improved by demonstration and by providing awareness by the health care worker.
\end{abstract}

\section{INTRODUCTION}

Bronchial asthma and Chronic Obstructive Pulmonary Disease (COPD) are estimated to affect about 300 and 210 million people respectively worldwide (World Health Organization, 2014). Drug therapy remains the mainstay treatment of asthma and COPD. The inhalation route is widely used for the treatment of obstructive lung diseases. The use of inhalational drugs allows drugs to reach directly to lungs by achieving high drug concentrations in the airway and reducing systemic adverse effects by minimizing systemic drug level (Şen et al., 2006). Thus, inhaled drug therapy maximizes therapeutic effect in chronic airway diseases as well as minimizing undesired side-effects. The National Heart, Lung and Blood Institute (NHLBI), World Health Organization (WHO), Global Initiative for Chronic Obstructive Lung Disease (GOLD) and Global

\footnotetext{
* Corresponding Author

A/5, Silver Park, Opp. New Sharda Mandir School, Near Shreyas Overbridge, Ambawadi, Ellis-bridge, Ahmedabad-380006, India. Phone: +91-9998369809, E-mail ID: alpeshkchauhan@gmail.com
}

Initiative for Asthma (GINA) recommended that bronchodilator medications play a central role to give symptomatic relief in COPD and asthma patients (Global Initiative for Chronic Obstructive Lung Disease, 2014; Global Initiative for Asthma, 2014). Metered Dose Inhaler (MDI) is the most commonly used device in daily management of asthma as it is portable, easy to be used, and cheaper (Deerojanawong et al., 2009). One of the most common disadvantages of MDI use is the specific inhalation technique necessary for the proper use of these inhaler devices. Proper inhalation technique is an important factor in achieving adequate drug level and improper technique leads to insufficient drug level at the target site (Haughney et al., 2010). WHO has suggested steps to use MDI which are as follows (* suggests essential step) (de Vries et al., 1994):

1. Cough up as much sputum as possible.

2. Shake the aerosol before use.*

3. Hold the aerosol as indicated in the manufacturer's instructions (this is usually upside down).

4. Place the lips tightly around the mouthpiece.*

5. Tilt the head backward slightly. 
6. Breathe out slowly, emptying the lungs of as much air as possible.*

7. Breathe in deeply and activate the aerosol, keeping the tongue down.

8. Hold the breath for ten to fifteen seconds.*

9. Breathe out through the nose.*

10. Rinse the mouth with warm water.

There are a number of studies done to evaluate the use of drugs used in treatment of asthma and COPD. However, there are only few studies done to evaluate the technique of use of MDI. The proper technique of use of MDI is of prime importance to achieve target therapeutic response. Hence, this study was undertaken to evaluate the proper technique of use of MDI and to correlate the factors responsible for the improper use of inhalation technique in patients of asthma or COPD patients at a tertiary care teaching hospital.

\section{MATERIALS AND METHODS}

The study was started after taking permission from the Institutional Ethics Committee. This cross-sectional study was conducted in outpatient department and indoor wards of TBCD department of Civil Hospital, Ahmedabad for duration of 4 months. It was carried out in the adult patients of either gender diagnosed to have asthma and COPD who are prescribed inhalation agents in form of MDI. Pregnant females and children were excluded from the study. The data like demographic details, details of the drug treatment, details regarding learning of inhalation technique of MDI were recorded in the pre-validated case record form (CRF) after taking personal interview. A checklist was prepared for inhalational technique of MDI use as per WHO suggested steps. The patients were requested to carry out demonstration on how they use the MDI so that the steps could be assessed and compared with the checklist about the inhalation technique by the investigator. Recorded information of patients was entered using Microsoft Excel Worksheet. Data was analyzed using Graph Pad InStat version 3. The demographic details were analysed. The steps of inhalation technique of use of MDI were also analysed and correlated with the demographic details.

\section{RESULTS}

A total 193 patients of which 128 COPD and 65 asthma were included in the study. Out of this, 33 indoor patients and 160 outdoor patients were included. The mean age of the patients was $43.7 \pm 13.6$ years (mean \pm S.D.) with a male : female ratio of 2.5:1. Majority of the patients achieved primary education $(34 \%)$ followed by higher secondary education (22\%), illiteracy $(17 \%)$, secondary education (15\%) and graduation (12\%). Majority of the patients were labourers $(46.1 \%)$ followed by housewives $(25.4 \%)$, vendors $(9.8 \%)$ and retired persons $(6.7 \%)$. The mean income of the patients was $\neq 8697 \pm 4005$ (mean \pm S.D.). Commonly used drugs by inhalation route by means of MDI were ipratropium bromide + salbutamol sulphate $(35.8 \%)$, budesonide + formoterol $(18.7 \%)$, fluticasone propionate + formoterol $(16.6 \%)$, salmeterol + fluticasone (12.4\%), tiotropium bromide $(8.8 \%)$ and levosalbutamol + ipratropium bromide (7.8\%). About 94.8\% patients were taught about the inhalation technique by the physicians. Almost half $(50.8 \%)$ patients actually performed the steps of use of MDI technique in front of the physician.

Only 70 out of 193 patients (36.3\%) followed all the essential steps of MDI use. As shown in the figure 1, majority of patients $(98.4 \%)$ followed the step to place the lips tightly around the mouthpiece and to hold the aerosol as indicated in the manufacturer's instructions (94.3\%). While the steps least followed were coughing up as much sputum as possible $(14.5 \%)$, breathing out through nose $(15 \%)$ and rinsing the mouth after use $(22.8 \%)$.

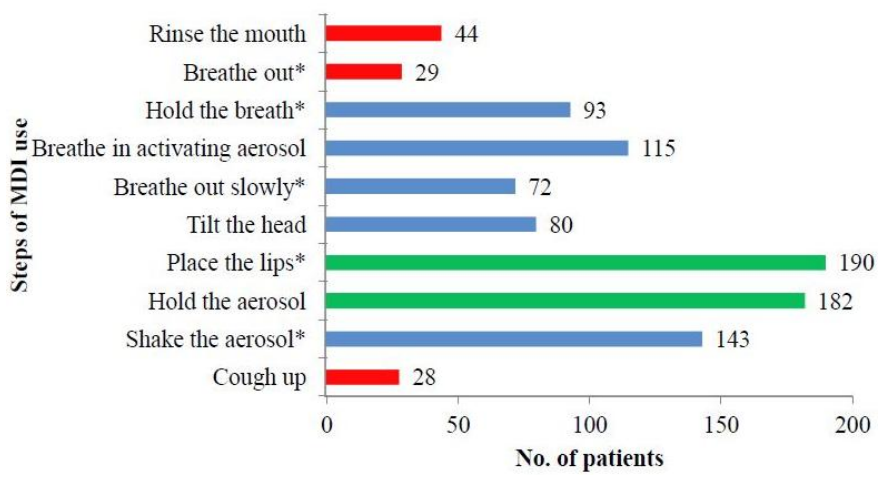

Fig. 1: Number of patients following each step of inhalation technique using metered dose inhaler.

Essential steps of MDI use were followed in $21.2 \%$ illiterate people, $43.1 \%$ people having primary education, $10 \%$ people having secondary education, $45.2 \%$ people having higher secondary education and $56.5 \%$ graduates. Patients having secondary education followed the essential steps significantly less compared to graduates $(p<0.01)$, higher secondary educates $(p<0.001)$, primary educates $(p<0.001)$ and illiterates $(p<0.05)$. Otherwise there was no significant difference between the education groups. Around 29\% male and $54.5 \%$ female patients followed all the essential steps. There was also no significant difference between male and female for following the essential steps $(p=0.137)$.

However, the patients aging more than 40 years $(32.7 \%)$ followed the essential steps significantly more compared to the patients aging less than or equal to 40 years $(40.4 \%)(p=0.02)$. Patients using MDI for 1 year or less (56.4\%) followed the essentials steps significantly $(p=0.006)$ more than who were using it for more than 1 year $(31.2 \%)$. Patients not being hospitalised $(66.7 \%)$ followed the essential steps significantly $(p=0.005)$ more compared to patients who had been hospitalised for at least once $(32.6 \%)$.

Patients who knew about the disease they were suffering from $(50 \%)$ followed the essential steps significantly $(p=0.048)$ more than who did not know (32.2\%). Patients getting instructions 
for the inhalation technique more than 1 times per year $(52.1 \%)$ followed the essential steps significantly $(p=0.014)$ more compared to patients who got instructions for less than or equal to 1 time per year $(31 \%)$.

\section{DISCUSSION}

Asthma and COPD are the common respiratory disease affecting patients worldwide (World Health Organization, 2014). Bronchodilators are the primary treatment used to treat asthma and COPD (Şen et al., 2006). The drugs commonly used include beta 2 adrenergic receptor agonists like salbutamol, salmeterol, terbutaline and formoterol; anti-cholinergics like ipratropium bromide and triotropium bromide and inhalation steroids like fluticasone and budesonide (Barnes, 2012).

The most common and effective route used for treating these patients is inhalation route including MDI (Deerojanawong et al., 2009). There are a lot of advantages associated with the use of MDI which include site specific delivery and less systemic adverse drug reactions. But a problem associated with the use of MDI is that a proper technique is required for inhalation. Asynchrony during inhalation leads to less delivery of drug at the site (Haughney et al., 2010). Literacy rate in India is $74.04 \%$ (Census of India, 2011).

Poor knowledge and literacy might lead to faulty technique for using MDI. Hence, this study was undertaken to assess the technique of use of MDI using WHO suggested steps (de Vries et al., 1994) and to correlate the factors associated with improper use. Although prevalence of asthma is higher compared to COPD, COPD causes a heavier disease burden due to the greater severity of exacerbations, greater number of hospitalizations, uniform progression of the disease (Yawn, 2009). Asthma is more prevalent in children (Rudd and Moorman, 2007) and as per the inclusion criteria of this study only adult patients were included, hence the study had more of COPD patients than asthma. Most of the patients in this study were outdoor patients, because most cases of asthma and COPD can be treated in outpatient department. The severe patients were required to get hospitalised who are managed by means of a nebulizer.

Only $36.3 \%$ patients followed all the essential steps of MDI use. This might be because of the ignorance. There might also be lack of proper instructions by the physician (Interiano and Guntupalli, 1993). As compared with study done by Şen et al. where $65.5 \%$ patients showed proper inhalation technique, our study had only $36.3 \%$ following essential steps (Şen et al., 2006). Most of the patients followed the step to place the lips tightly around the mouthpiece and to hold the aerosol as indicated in the manufacturer's instructions.

This might be because the most patients see the position of MDI in the picture which might reinforce them to follow these steps. While the steps least followed were coughing up as much sputum as possible, breathing out through nose and rinsing the mouth after use. However, some steps like these are difficult to demonstrate and hence are given less importance while giving instructions by physician. Deerojanawong et al. suggested that step of breathing in deeply and activate the aerosol were the most common steps which were usually missed (Deerojanawong et al., 2009). This might be responsible for less delivery of a drug at site of action (Haughney et al., 2010).

Our study suggested that older patients ( $>40$ years) followed essential steps more than younger patients ( $\leq 40$ years). However, Şen et al. and Chorão et al. suggested younger patients followed the inhalation technique more properly than older patients while Hesselink et al. showed no significant difference between age groups (Şen et al., 2006; Chorão et al., 2014; Hesselink et al., 2007). Our study suggested no statistical significant difference for proper inhalation technique between male and female which was similar to a study done by Hesselink et al. (Hesselink et al., 2007). No significant difference between education levels for proper inhalation technique was also found by Hesselink et al. and Şen et al. (Hesselink et al., 2007; Şen et al., 2006). However, our study suggested that patients having secondary education followed the essential steps significantly less compared to patients having primary education $(p<0.001)$, graduation $(p<0.01)$ and illiteracy $(p<0.05)$. Otherwise there was no significant difference between educational groups for proper inhalation technique. Illiterate patients and patients having primary education might follow the instructions because of the fact that they perceive physician as their saviour and follow their instructions blindly. Also, graduate patients might follow them as they might know the importance of proper inhalation technique due to their education. Chorão et al. showed that patients having lower education have more chances to miss the steps (Chorão et al., 2014).

Patients followed the essential steps more commonly who were using MDI for less duration, which might be due to fresh instructions regarding MDI use in their minds. Chances of following the essential steps were higher in the patients who had not been hospitalized. The reason behind it might be the patients following the essential steps have more efficacy and hence less possibility of hospitalization. Patients having knowledge about the disease, they were suffering from, followed the essential steps more commonly as they might be more aware about the importance of the inhalation technique. Frequent instructions about inhalation technique increase the chances of following the essential steps that might be because of the reinforcement regarding the technique.

This study was a cross sectional study in which we did not follow up the patients for efficacy end points. Thus, we were not able to measure the impact of proper inhalation technique of MDI on the efficacy of the drugs on the outcome of the diseases. We could also educate the patients regarding inhalation technique of MDI use by means of various educational interventions and could differentiate between them. However, this study gave information regarding inhalation technique of MDI use and its relation with few related factors like age, gender and education level. However further studies are required to conclude about the factors responsible and intervention to improve the use of MDI. 


\section{CONCLUSION}

Only few patients followed all the essential steps of inhalation technique of MDI. This can be improved by proper education of the patients by means of actual demonstration, showing pictures, performing in front of physician and repeated training for the proper inhalation technique which can improve efficacy, compliance and quality of life in asthma and COPD patients.

\section{REFERENCES}

Barnes PJ. 2012. Pulmonary Pharmacology. In: Brunton LL, ed. Goodman \& Gilman's the pharmacological basis of therapeutics. New York: McGraw-Hill. pp.1031-66.

Census of India, 2011. Available at: http://www.censusindia. gov.in/2011-prov-results/indiaatglance.html [Accessed 06 June 2015]

Chorão P, Pereira AM, Fonseca JA. Inhaler devices in asthma and copd - an assessment of use and patient preferences. Respir Med, 2014; 108(7):968-75.

de Vries TPGM, Henning RH, Hogerzeil HV, Fresle DA. 1994. Guide to Good Prescribing. A practical manual. [ONLINE] Available at: http://apps.who.int/medicinedocs/pdf/whozip23e/whozip23e.pdf [Accessed 19 September 2015]

Deerojanawong J, Sakolnakorn VP, Prapphal N, Hanrutakorn C, Sritippayawan S. Evaluation of Metered-Dose Inhaler Administration Technique among Asthmatic Children and Their Caregivers in Thailand. Asian Pacific Journal Of Allergy And Immunology, 2009; 27:87-93.

Global Initiative for Asthma. Pocket guide for asthma management and prevention. Available at: http://www.ginasthma.org/ local/uploads/files/GINA_Pocket_2014_Jun11.pdf [Accessed 12 December 2014]

Global Initiative for Chronic Obstructive Lung Disease. Global strategy for the diagnosis, management and prevention of Chronic Obstructive Pulmonary Disease. Available at: http://www.goldcopd.org/ uploads/users/files/GOLD_Report2014_Feb07.pdf [Accessed 12 December 2014]
Haughney J, Price D, Barnes NC, Virchow JC, Roche N, Chrystyn H. Choosing inhaler devices for people with asthma: Current knowledge and outstanding research needs. Respiratory Medicine, 2010; 104:1237-45.

Hesselink AE, Brenda W.J.H. Penninx, Hanneke A.H. Wijnhoven, Didi M.W. Kriegsman and Jacques Th.M. van Eijk. Determinants of an incorrect inhalation technique in patients with asthma or COPD. Scand J Prim Health Care, 2007; 19:255-60.

Interiano B, Guntupalli KK. Metered-dose inhalers. Do health care providers know what to teach? Arch Intern Med, 1993; 153(1):81-5.

Rudd RA, Moorman JE. Asthma incidence: data from the national health interview survey, 1980-1996. J Asthma, 2007; 44:65-70.

Şen E, Gönüllü U, Ekici Z, Kurşun N. Assessment of inhaler technique and treatment compliance of hospitalized patients and outpatients in a university hospital. Ankara Üniversitesi Tıp Fakültesi Mecmuas1, 2006; 59:1-6.

World Health Organization. Available at: http://www.who.int/ gard/publications/chronic_respiratory_diseases.pdf [Accessed 12 December 2014]

Yawn BP. Differential Assessment and Management of Asthma vs Chronic Obstructive Pulmonary Disease. Medscape J Med, 2009; 11(1):20.

\section{How to cite this article:}

Chauhan A, Patel P, Gandhi A, Desai M. An evaluation of Metered-Dose Inhaler Administration Technique in Patients of Asthma and Chronic Obstructive Pulmonary Disease. J App Pharm Sci, 2016; 6 (02): 115-118. 